S. W. Lam

N. Q. Nguyen

K. Ching

M. Chapman

R. J. Fraser

R. H. Holloway

\section{Gastric feed intolerance is not increased in critically ill patients with type II diabetes mellitus}

Published online: 7 July 2007

(C) Springer-Verlag 2007

The online version of the original can be found at http://dx.doi.org/10.1007/s00134-007-0712-1.

S. W. Lam · M. Chapman

Royal Adelaide Hospital, Department of Intensive Care,

North Terrace, Adelaide, 5000, SA, Australia

N. Q. Nguyen $(-$ K. Ching $\cdot$ R. H. Holloway

Royal Adelaide Hospital, Department of Gastroenterology,

North Terrace, Adelaide, 5000, SA, Australia

e-mail: Qnguyen@mail.rah.sa.gov.au

Tel.: +61-8-82224000

Fax: +61-8-82225885

N. Q. Nguyen · R. J. Fraser · R. H. Holloway

Royal Adelaide Hospital, University Department of Medicine,

North Terrace, Adelaide, 5000, SA, Australia

R. J. Fraser

Repatriation General Hospital, Department of Gastroenterology,

Adelaide, 5041, SA, Australia

\section{Intensive Care Med (2007)}

DOI 10.1007/s00134-007-0712-1

Owing to an error in production, the names of the first two authors appeared in the wrong order. This mistake is corrected here.

S. W. Lam

N. Q. Nguyen

K. Ching

M. Chapman

R. J. Fraser

R. H. Holloway 